\title{
Social Relationships in Free-Ranging Male Macaca arctoides
}

\author{
Christin Richter • Lieke Mevis • \\ Suchinda Malaivijitnond • Oliver Schülke • \\ Julia Ostner
}

Received: 29 June 2008 / Accepted: 7 May 2009 / Published online: 21 July 2009

(C) The Author(s) 2009. This article is published with open access at Springerlink.com

\begin{abstract}
Macaque social relationships differ greatly between species. Based on captive studies that focus mainly on females, researchers have classified stumptail macaque (Macaca arctoides) social relationships as tolerant, as indicated by a high rate of affiliation, frequent aggression, and symmetrical conflicts. To accumulate more data on male social relationships, which are relatively understudied, and to generate comparative data, we investigated male social relationships in a provisioned group of 68 free-ranging, naturally dispersing stumptail macaques in southern Thailand. We collected continuous focal animal and ad libitum data on 7 adult and 2 subadult males, recording social behavior during 283 contact hours between December 2006 and March 2007. Stumptail macaques of this population were less tolerant than predicted based on previous studies on captive groups: Rates of spatial proximity, affiliation, and aggression were low, most males directed affiliative behavior toward higher-ranking males, and conflicts were generally of low intensity and relatively asymmetrical. Thus, male stumptail macaques of the focal group appear to differ in their social style from a previous study of a captive group that
\end{abstract}

\footnotetext{
C. Richter $(\square) \cdot$ O. Schülke $\cdot$ J. Ostner

Courant Research Center for Evolution of Social Behaviour,

Georg-August-University Göttingen,

Kellnerweg 6, 37077 Göttingen, Germany

e-mail: celestina.richter@gmail.com

C. Richter

Institute of Biology II, University of Leipzig, 04103 Leipzig, Germany

C. Richter $\cdot$ L. Mevis $\cdot$ O. Schülke $\cdot$ J. Ostner

Integrative Primate Socio-Ecology,

Max Planck Institute for Evolutionary Anthropology,

04103 Leipzig, Germany

L. Mevis

Department of Biology, University of 3508 TC, Utrecht, the Netherlands

S. Malaivijitnond

Primate Research Unit, Department of Biology, Faculty of Science, Chulalongkorn University,

Bangkok, Thailand
} 
mainly comprised of females. In some traits, they are even more intolerant than rhesus macaques, an intensively studied intolerant macaque species. We also compare our data on stumptail macaque males to those on other male macaques, but available data are too sparse to draw final conclusions.

Keywords dominance $\cdot$ male stumptail macaques $\cdot$ social relationships $\cdot$ social style social tolerance

\section{Introduction}

Social relationships between individuals are the consequences of patterns of social interactions between members of a social group (Hinde 1976; Kappeler and van Schaik 2002). Among primates the quality of social relationships varies widely, entailing patterns of spatial proximity, affiliation, aggression, reconciliation, dominance characteristics, and nepotism (Chaffin et al. 1995; de Waal and Luttrell 1989; Matsumura 1999; Thierry 2000; Thierry et al. 2000). Researchers have intensively studied female social relationships during the last decades, whereas they have focused less on male-male relationships in the majority of primate species (but see Cooper and Bernstein 2002; Hill 1994; Hill and van Hooff 1994; van Hooff and van Schaik 1994). Investigations of male social relationships have concentrated particularly on specific patterns such as agonistic support or affiliation (Silk 1992, 1994; Widdig et al. 2000), but researchers have rarely assessed whole sets of behavioral traits. Here we present data on affiliative and agonistic relationships among male stumptail macaques from a provisioned population with a natural dispersal regime.

Male social relationships vary from antagonistic to tolerant, depending on the species (Thierry 2000), the sex ratio in the group (Caldecott 1986; Hill 1994), or sometimes the habitat (Starin 1994). Kinship and male philopatry may facilitate male cooperation and affiliation, but are not a necessary prerequisite for these behavioral patterns (Jack and Fedigan 2004; Langergraber et al. 2007; Ostner and Kappeler 2004; Packer 1979; Packer et al. 1991; Pope 1990; Silk 1992). In general, affiliative and cooperative relationships are rather uncommon among primate males, but they exist in chimpanzees (Pan troglodytes: Goodall 1965, 1986), woolly spider monkeys (Brachyteles arachnoides: Strier 1994), red colobus (Colobus badius: Struhsaker 1975; Struhsaker and Leland 1987), ring-tailed lemurs (Lemur catta: Gould 1997), white-faced capuchins (Cebus capucinus: Fedigan and Jack 2004), hamadryas baboons (Papio hamadryas: Kummer 1968), yellow baboons (Papio cynocephalus cynocephalus: Noë and Sluijter 1995), and anubis baboons (Papio cynocephalus anubis: Noë and Sluijter 1995).

Male macaques promise to be especially suitable for investigating the causes of variation in male social relationships. The $c a$. 20 species show great uniformity in their social organization and demography. All species live in multimale, multifemale groups. Females are the philopatric sex, forming strong bonds within matrilines, whereas males disperse from their natal group and continue to transfer periodically. Despite this uniformity, macaques show pronounced variation in the quality of social relationships or social style (Thierry 2004), ranging from despotic-intolerant to despotic-tolerant. Thierry (2000) classified macaques in a 4-grade system according 
to their social style. Species-specific relationships in the first 2 grades are thought to be less tolerant than in grade 3 and 4 species (Thierry 2000). For example, affiliation between males is rare in the intolerant rhesus (Macaca mulatta) and Japanese macaques (Macaca fuscata; both grade 1), whereas it is frequent in the more tolerant bonnet (Macaca radiata) or Barbary macaques (Macaca sylvanus; both grade 3) (Caldecott 1986; Hill 1994; Silk 1994).

According to socioecological theory, tolerance should be less common between males than between females in socially living primate groups (van Hooff and van Schaik 1992, 1994; van Schaik 1996; Wrangham 1980). Social relationships are determined by ecological patterns, such as the monopolizability and quality of limiting resources (Sterck et al. 1997; van Schaik 1989; Wrangham 1980), and key resources are known to differ between females and males. Females compete for food, whereas males compete primarily for access to fertile females, a limited and unsharable resource (Clutton-Brock 1989; Emlen and Oring 1977; Wrangham 1980). Consequently, we expect social tolerance less often in males. However, tolerance among male macaques exists and researchers have proposed several nonmutually exclusive hypotheses to account for the variation in social style. Tolerance may be a means of preventing potentially destabilizing revolutionary coalitions (Macaca thibetana: Berman et al. 2007), the cause of a stalemate between highly competitive males bearing dangerous weapons (Macaca sylvanus: Preuschoft and Paul 2000), or the consequence of inbreeding leading to increasing paternal care behavior that inhibits male-male aggression (Caldecott 1986).

Stumptail macaques (Macaca arctoides) have been the focus of several studies of social style in captive and semifree-ranging conditions and have consistently been classified as ranging on the tolerant or relaxed side of the continuum (Butovskaya 1993; de Waal and Luttrell 1989; de Waal and Ren 1988). Accordingly, Thierry classified them as a grade 3 species (Thierry 2000, 2007a, b; Thierry et al. 2000). However, this classification is based mainly on data from females. Because males are the emigrating sex in macaques, their social relationships may be more affected by captivity where group composition often is regulated to reduce tension in the group and to maximize breeding success (Butovskaya 1993; de Waal and Luttrell 1989; de Waal and Ren 1988; MacKenzie et al. 1985). Hence it seems important to study males in more natural conditions, where stable groups can contain more males and where males are able to avoid each other spatially. Thus, we aimed to investigate the quality of social relationships among stumptail macaque males. The data will help to improve our understanding of social style variation and will provide essential data on so far understudied macaque male-male social relationships.

Based on the hypothesis that male stumptail macaques exhibit relaxed social relationships as described for the species in the literature, we test predictions generally proposed to differentiate between tolerance levels of macaque species (Chaffin et al. 1995; de Waal and Luttrell 1989; Hemelrijk and Gygax 2004; Matsumura 1999; Thierry 2000). Specifically, we predict that compared to intolerant macaques, such as rhesus macaques, stumptail macaque males 1) form a shallow hierarchy with low predictability of aggression direction, 2) approach each other frequently, 3) approach dominants and subordinates equally often, 4) have frequent affiliative interactions such as grooming, 5) show no rank effect in grooming preference, 6) frequently show aggression but at low intensity, and 7) are characterized by a high rate 
of counteraggression. To describe the social style of males in our focal group further, we also investigate patterns of grooming among adjacent ranks and grooming interchange (Barrett et al. 1999; Schino et al. 2003; Seyfarth 1977).

\section{Methods}

Study Site and Subjects

We studied a multimale, multifemale group of stumptail macaques (Macaca arctoides) living near the Wat Khuha Santayaram monastery (Wat Tham Khao Daeng) in Nakhon Si Thammarat Province, southern Thailand $\left(8^{\circ} 14^{\prime} \mathrm{N}, 9^{\circ} 52^{\prime} \mathrm{E}\right.$; Malaivijitnond and Hamada 2005). The monastery lies at the foot of a hill, which is characterized by numerous caves and covered by dense vegetation. At the temple site, 2 groups of stumptail macaques are sympatric with a group of longtail macaques (Macaca fascicularis). The monkeys descend from the hill to the temple grounds every day. The monks of the temple feed the monkeys once or twice a week, and local villagers feed them about once per week.

At the beginning of the study, the focal group consisted of 68 individuals: 7 adult males, 2 subadult males, 15 adult females, 33 juveniles, and 11 infants. All 7 adult and the 2 subadult males were subjects of focal animal observation. We estimated age on the basis of morphological characters, e.g., pelage, facial and sex skin color, nipple color and length, body size in both sexes, and descent of testes into the scrotum in males. Subadult males had a slender appearance, were sexually active, and had testes of adult size and an entirely filled scrotum. One adult male immigrated into the focal group $2.5 \mathrm{wk}$ before the end of the study and we did not include him in the analysis. Kin relationships among the group members were unknown.

\section{Observation Methods}

We collected data between December 2006 and March 2007. We observed focal individuals continuously during 20-min periods, recording social interactions (Altmann 1974; Martin and Bateson 1993) via an ethogram based on earlier definitions of macaque behavior (Bertrand 1969; de Waal and Luttrell 1989; van Hooff 1967). We conducted a part of the observations in the context of provisioning because observation was limited to the time the monkeys spent at or around the temple area, due to the inaccessibility of the hill. We semirandomized the order of the focal individuals to ensure that we observed all males equally often during all times of the activity period. In addition, we collected ad libitum data (Altmann 1974) on social behavior for hierarchy construction. During $283 \mathrm{~h}$ of contact time, we collected $134.3 \mathrm{~h}$ of focal data, resulting in a mean of 14.9 (SD: 0.2) h per focal male.

\section{Behavioral Measures}

Approach We defined an approach as entering the 1.5-m range of a stationary partner and staying for $\geq 15 \mathrm{~s}$. We calculated the approach rate for each focal 
individual as the number of approaches by the focal individual to other males per focal hour. To assess the direction of approaches, we calculated the Up/Down Index (Castles et al. 1996). An Up/Down Index $>0.5$ indicates a preference to approach dominants more often; a value $<0.5$ indicates a preference of rank downward approaches; and an index of 0.5 indicates no preference. We calculated the Up/Down Index for each focal male, except for the highest and lowest ranking males because they can approach in only 1 direction. Approaches in a feeding context referred to foraging behavior and ingestion of any kind of food.

Grooming We calculated grooming rate as the number of grooming bouts given by the focal male to all other males per focal hour. A grooming bout may consist of several grooming actions, which can be performed by only 1 individual or by both dyad partners by either grooming simultaneously or consecutively. If a grooming bout was interrupted for $>20 \mathrm{~s}$, we scored it as a new bout. We calculated grooming duration (\%) as the time of male-male grooming given by the focal male per hour of focal observation, multiplied by 100 . To assess whether males directed grooming up or down the hierarchy, we applied the Up/Down Index to grooming. We calculated reciprocal grooming per dyad as the lower value of grooming actions performed by 1 individual of a certain dyad divided by the total number of grooming actions in the dyad, then multiplied by 2 (Vervaecke et al. 2000).

Agonistic Interactions Agonistic interactions, or conflicts, consisted of $\geq 1$ submissive or aggressive behavioral element. An individual was submissive if it showed $\geq 1$ of the following: Make Room (the monkey moves slightly away from another monkey; often only the upper part of the body is moved), Give Ground, Flee, Crouch, Silent Bared Teeth (van Hooff 1967), Teeth Chatter/Bared Teeth (an intermediate between Teeth Chatter and Bared Teeth). We counted only Present and Dog-Like Present (Present with 1 hind leg lifted) as submissive when preceded by aggression, or when they cooccurred with 1 of the other submissive elements. To facilitate data comparison, we classified all dyadic conflicts involving aggression according to the intensity of aggression used (threat and attack), per de Waal and Luttrell (1989), with slight modifications according to our ethogram. We calculated threat rate as the number of aggressive conflicts that did not exceed threat intensity initiated per hour of focal observation. Threats included Stare, Open Mouth, Lunge, Slap, Grab, Mock Bite, and in addition Pretend Slap, Push, and Pull. We calculated attack rate as the number of aggressive conflicts exceeding threat intensity initiated per hour of focal observation. This included Chase and Bite (de Waal and Luttrell 1989). We calculated aggression rate as the number of aggressive conflicts of any intensity initiated per hour of focal observation. We calculated the percentage of severe conflicts as a ratio of the attack rate to aggression rate multiplied by 100 . The predictability of aggression direction (\%) is calculated as the difference between 100\% and the Directional Inconsistency Index (DII). The DII was calculated for initiated aggressive conflicts on the level of male-male dyads (Chaffin et al. 1995; de Waal and Luttrell 1989). We calculated the percentage of counteraggression received as percentage of aggressive conflicts of any intensity initiated by the focal individual to which the recipient responded with aggression of any intensity (de Waal and Luttrell 1989). 
Agonistic Support We calculated support rates for both directions of each dyad as the number of agonistic supports divided by the number of occasions for support (Schino et al. 2007). The number of occasions in which individual $\mathrm{X}$ could potentially support individual $\mathrm{Y}$ was the total number of aggressions involving $\mathrm{Y}$ (both aggression given and received) minus the number of aggressions between $\mathrm{X}$ and Y. We scored supports as either victim or aggressor support. Support rates include only supports between males against another male.

\section{Dominance Hierarchy}

We constructed a dominance hierarchy on the basis of 258 dyadic decided conflicts from focal and ad libitum data (Table I). Decided conflicts were either unprovoked submission or aggression followed by submission. To assess linearity of the hierarchy, we used the corrected Landau Index $h$, which accounts for the number of unknown relationships (de Vries 1995). We calculated the Directional Consistency Index to evaluate whether using decided conflicts for hierarchy construction was appropriate. The index ranges from 0 to 1 , with 1 expressing maximum unidirectionality (van Hooff and van Wensing 1987). To construct the dominance hierarchy, we calculated Normalized David Scores (NormDS), corrected for variation in interaction frequencies $\left(D_{\mathrm{ij}}\right.$; de Vries 1998; de Vries et al. 2006; Gammell et al. 2003), as this method has been shown to be the most efficient (Gammell et al. 2003; Hemelrijk et al. 2005). NormDS are measured on a continuous scale. The slope of the least-square linear regression of NormDS plotted in rank order provides a measure of the steepness of hierarchy. One can refer to steepness as the difference in overall winning success between adjacently ranked individuals. As the measure of steepness ranges between 0 and 1, these differences are small when steepness is close to 0 , indicating an egalitarian society, and large when steepness reaches 1 , indicating a strictly despotic society (Vervaecke et al. 2007). We assigned rank 1 to the highest-ranking individual and rank 9 to the lowest-ranking one. We observed no rank changes during the course of the study.

Table I Winner-loser matrix based on outcome of decided conflicts

\begin{tabular}{|c|c|c|c|c|c|c|c|c|c|}
\hline Dominance Rank & 1 & 2 & 3 & 4 & (5) & 6 & (7) & 8 & 9 \\
\hline 1 & $*$ & 22 & 18 & 8 & 11 & 2 & 18 & 3 & 3 \\
\hline 2 & 3 & * & 8 & 5 & 7 & 1 & 32 & 2 & 6 \\
\hline 3 & 1 & & * & 3 & 1 & 0 & 11 & 1 & 0 \\
\hline 4 & & & 1 & * & 7 & 1 & 2 & 1 & 2 \\
\hline (5) & & & 1 & 1 & * & 7 & 11 & 8 & 1 \\
\hline 6 & & & & & & $*$ & 1 & 14 & 6 \\
\hline (7) & & & & 7 & & & $*$ & 2 & 3 \\
\hline 8 & 1 & & & 1 & 1 & 1 & & * & 10 \\
\hline 9 & & & 1 & & & & 1 & & $*$ \\
\hline
\end{tabular}

Focal and ad libitum data; winners are indicated by vertical rank numbers, losers by horizontal rank numbers. Parentheses indicate subadult males 


\section{Data Analyses}

We used exact Wilcoxon matched-pairs signed-ranks tests to compare individuals' values for the Up/Down Index of approaches and grooming with 0.5 because 0.5 indicates that the behavior is equally directed up and down the hierarchy. To analyze grooming patterns, we applied row-wise matrix correlations using Spearman rank (row-wise $R r$ test) instead of simple matrix correlations because all matrices were square and asymmetric and to take individual differences in a certain behavior into account (de Vries 1993, 1998). We based $p$-values on 10,000 permutations. We report right-tailed and left-tailed probabilities for positive correlations and negative correlations, respectively (Vervaecke et al. 2000).

To investigate whether adjacent ranks groomed more frequently, we used a row-wise $R r$ test of a rank distance matrix and a dually normalized symmetric grooming matrix. We normalized the symmetric grooming matrix containing the sum of grooming given in both directions via MatMan ${ }^{\mathrm{TM}}$ version 1.1.4. (Noldus 2003) by fitting homogeneous margins, setting the marginal totals to 100 (Freeman et al. 1992; Vervaecke et al. 2000). To investigate whether adjacent ranks groomed more reciprocally versus more distant dyads, we examined the correlation between the rank distance matrix and a symmetrical matrix of grooming reciprocities.

We tested potential interchange of grooming for support by investigating the correlation between a matrix of frequencies of grooming given and a matrix of amount of support received expressed as support rates. In addition, we investigated interchange of grooming for social tolerance by correlating a matrix containing grooming given with 1) a matrix containing the frequency of approaches in a feeding context, 2) a matrix containing the total duration of spatial proximity $(\leq 1.5 \mathrm{~m})$ in a feeding context, and 3$)$ a matrix of aggression (bouts) received.

We used only 2-tailed and nonparametric tests. In case of multiple testing, we tested overall $p$-values for significance by using Fisher's Omnibus Test (Haccou and Meelis 1997), abbreviated as $\chi^{2}$. We calculated standard deviations for the statistical population. We performed analyses in Excel ${ }^{\circledR}$ (Microsoft 2002), SPSS $\odot 13.0$ (SPSS Inc. 2004), and MatMan ${ }^{\mathrm{TM}} 1.1 .4$ (Noldus 2003). We set the $\alpha$ level for rejecting the null hypothesis to 0.05 . Sample size for durations and rates was $N=9$, unless otherwise stated.

\section{Results}

\section{Dominance Hierarchy}

The winner-loser matrix produced a significant linearity $h^{\prime}$ of 0.71 ( $p$-right $\left.<0.01\right)$. Directional Consistency of the matrix was 0.89 . The 2 top-ranking males with highest NormDS values, and thus a high overall winning success, ranked far above all other males (Fig. 1). The steepness of the hierarchy is 0.58 and significant ( $p$-right $<0.001 ; 2000$ permutations). The data were well predicted by the regression function $\left(R^{2}=0.89\right)$. 
Fig. 1 Rank distances indicated by Normalized David Scores (NormDS) and steepness of hierarchy (0.58).

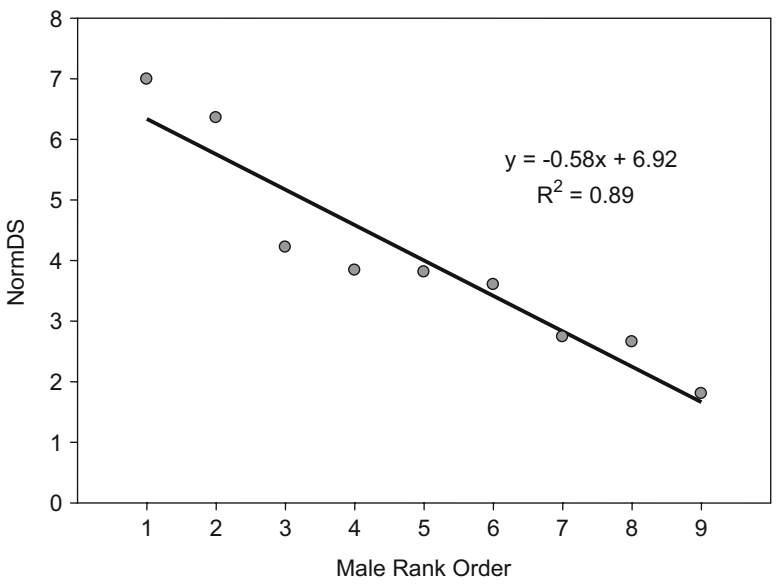

Spatial Proximity

Males approached other males at a mean rate of $1.25 \pm 0.45$ per hour, with a mean duration of staying in proximity of $1.83 \pm 0.40 \mathrm{~min}$. The Up/Down Index of approaches was $0.52 \pm 0.24$. Four males preferentially approached up the hierarchy, and 3 males down the hierarchy. Thus, there was no significant bias in approach direction (Wilcoxon signed-ranks test: $T=15, N=7, p=0.91$ ).

\section{Affiliation}

Males sat in body contact with other males at a mean rate of $0.05 \pm 0.07 / \mathrm{h}$, with a mean duration of $1.27 \pm 1.01 \mathrm{~min}$. Mean rate of grooming bouts was $0.15 \pm 0.12 / \mathrm{h}$, with a mean duration of $2.25 \pm 2.11 \mathrm{~min}$ per bout and usually only 1 grooming action per grooming bout (mean $=1.32$ ). Males spent $0.62 \% \pm 0.75 \%$ of their time grooming other males. Out of all 36 dyads, 47\% were never observed grooming (Fig. 2). The $\mathrm{Up} /$ Down Index of grooming was $0.80 \pm 0.34$, but there was no significant grooming direction for the group (Wilcoxon signed-ranks test: $T=23, N=7, p=0.141$; Fig. 3). Because all males groomed up the hierarchy except the third-ranking male, we reanalyzed the data excluding this male, as a giver and receiver of grooming, yielding a significant preference to groom up the hierarchy and a mean Up/Down Index of $0.93 \pm 0.11(T=21, N=6, p=0.031)$. The rank distance matrix does not correlate with the grooming matrix $\left(r_{\mathrm{s}(\mathrm{rw})}=0.06, p\right.$-right $\left.=0.37\right)$ or with the matrix of grooming reciprocities $\left(r_{\mathrm{s}(\mathrm{rw})}=0.16, p\right.$-right $\left.=0.18\right)$. Thus, individuals close in rank groomed each other neither more frequently nor more reciprocally than dyads of more distant ranks, as can be also seen in the grooming network (Fig. 2). Matrices of grooming given and support received do not correlate significantly $\left(r_{\mathrm{s}(\mathrm{rw})}=-0.01\right.$, $p$-left $=0.48)$. There is a significant correlation between the matrix of grooming given and 1) frequency of approaches in feeding context $\left(r_{\mathrm{s}(\mathrm{rw})}=0.26, p\right.$-right $\left.\left.=0.03\right), 2\right)$ duration of spatial proximity in feeding context $\left(r_{\mathrm{s}(\mathrm{rw})}=0.31, p\right.$-right $\left.=0.02\right)$, and 3 ) aggression received $\left(r_{\mathrm{s}(\mathrm{rw})}=0.23, p\right.$-right $\left.=0.04\right)$. After correcting all 6 matrix 
Fig. 2 Network of grooming frequencies. Numbers indicate the individual's rank; numbers in parentheses mark subadult males. Individuals are ordered counter-clockwise, with the highest ranking male on top. Each line indicates 1 grooming bout.

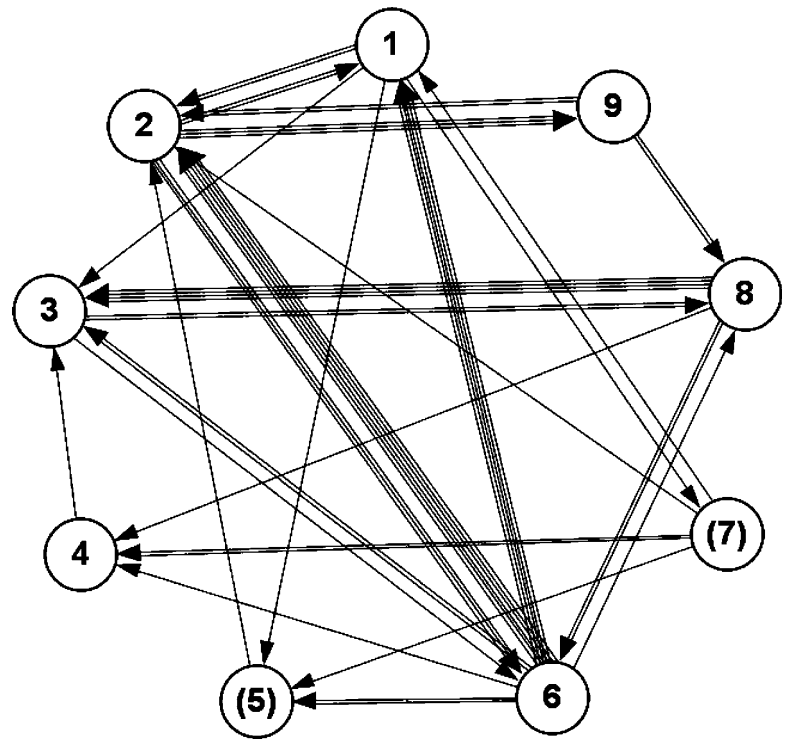

correlations for multiple testing, results remained significant (Fisher's Omnibus Test: $\left.\chi^{2}=28.74, \mathrm{df}=12, p=0.004\right)$.

\section{Agonistic Interactions}

Mean male-male (dyadic) conflict rate was $1.07 \pm 0.32 / \mathrm{h}$, and most conflicts occurred during feeding (73\%). About half (52\%) of the dyadic conflicts were solved by spontaneous submission. Dyadic conflicts involving aggression occurred at a mean rate of $0.51 \pm 0.25 / \mathrm{h}$. Most of the aggressive conflicts $(82 \%)$ were threats, i.e., at mild intensity, whereas only $18 \%$ were attacks. Only the 3 top-ranking males used aggression at attack intensity. Threat rate was $0.42 \pm 0.19 / \mathrm{h}$; attack rate, $0.09 \pm$ $0.13 / \mathrm{h}$ (Table II). The DII of initiated aggression was $7.2 \% \quad(N=69$ aggressive

Fig. $3 \mathrm{Up} /$ Down Index of grooming. An index $>0.5$ indicates a tendency to groom dominants preferentially, an index $<0.5$ a tendency to groom subordinates preferentially. Note that the index cannot be calculated for the highest and lowest ranking individual. The third-ranking individual never groomed up the hierarchy; thus its index equaled 0 .

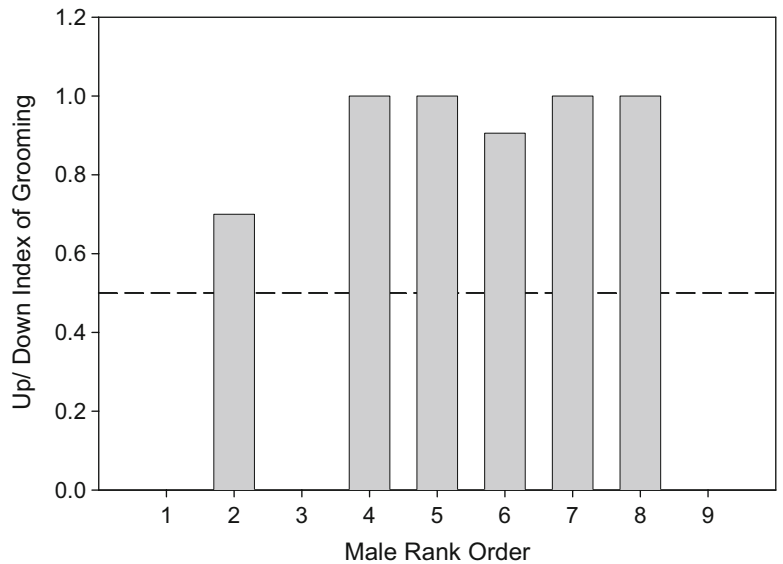


Table II Comparative data of male stumptail macaques (this study; natural but provisioned conditions), rhesus macaques (Macaca mulatta; captive, 83\% females), and stumptail macaques (Macaca arctoides; captive, $86 \%$ females), used in Fig. 4

\begin{tabular}{|c|c|c|c|c|c|c|}
\hline & \multicolumn{2}{|c|}{ Rhesus (Rh) } & \multicolumn{2}{|c|}{ Stumptail males (StM) } & \multicolumn{2}{|c|}{ Stumptails (St) } \\
\hline & $N$ & Mean \pm SD & $N$ & Mean \pm SD & $N$ & Mean \pm SD \\
\hline Approach rate (per h) & 24 & $9.73 \pm 4.87^{\mathrm{a}}$ & 9 & $1.25 \pm 0.45$ & 14 & $18.01 \pm 6.47^{\mathrm{a}}$ \\
\hline Grooming duration (\%) & 24 & $7.2 \pm 3.2^{\mathrm{a}}$ & 9 & $0.62 \pm 0.75$ & 14 & $18.5 \pm 10.2^{\mathrm{a}}$ \\
\hline Threat rate (per h) & 24 & $1.36 \pm 0.69^{\mathrm{a}}$ & 9 & $0.42 \pm 0.19$ & 14 & $3.47 \pm 1.56^{\mathrm{a}}$ \\
\hline Attack rate (per h) & 24 & $0.41 \pm 0.23^{\mathrm{a}}$ & 9 & $0.09 \pm 0.13$ & 14 & $0.38 \pm 0.31^{\mathrm{a}}$ \\
\hline$\%$ of severe conflicts & 24 & $23.16^{\mathrm{a}, \mathrm{b}}$ & 9 & 17.65 & 14 & $9.87^{\mathrm{a}, \mathrm{b}}$ \\
\hline Predictability of aggression direction (\%) & & $\sim 96.9^{\mathrm{a}}$ & 69 & 92.8 & 534 & $91^{\mathrm{a}}$ \\
\hline Counteraggression $(\%)$ & 24 & $8.9 \pm 11.7^{\mathrm{a}}$ & 8 & $23.5 \pm 15.7$ & 14 & $18.6 \pm 10.8^{\mathrm{a}}$ \\
\hline
\end{tabular}

\footnotetext{
a de Waal and Luttrell (1989): Data refer to all partners (kin and nonkin), and in the case of rhesus to the natural group. Approach frequency and conciliatory tendency concern adult-adult interactions only; all other measures concern behavior toward individuals $1.5 \mathrm{yr}$ of age or older. Group composition: rhesus macaques: 4 adult males ( $\geq 5 \mathrm{yr}$ ), 20 adult females ( $\geq 4 \mathrm{yr}$ ); total group size ranged between 51 and 62 individuals. Stumptail macaques: 2 adult males, 12 adult females, total group size: 21 individuals

${ }^{\mathrm{b}}$ Calculated from data reported in the literature as the percentage of aggression at the attack level
}

interactions), resulting in a predictability of aggression direction of $92.8 \%$. The percentage of counteraggression received was $23.5 \% \pm 15.7 \% \quad(N=8$; Table II $)$. However, aggression occurred in only $48 \%$ of all dyadic conflicts, with counteraggression accounting for only $8 \%$ of all dyadic conflicts (of all conflicts with $\geq 1$ submissive or aggressive element). Polyadic conflicts among all-male conflict partners were rare, accounting for only $4 \%$ of the total number of male conflicts. Mean dyadic support rate was $0.01 \pm 0.04$ ( $N=36$ dyads). Thus, on average, males supported each other only once in 100 aggressive conflicts.

\section{Discussion}

Male-male social relationships in stumptail macaques are organized mainly by a strong skew in overall winning success toward the 2 highest-ranking males, which ranked far above all other males. The dominance gradient affected grooming relationships especially. Most males groomed up the hierarchy, a pattern also known for other male macaques (Silk 1994). That the third-ranking male never groomed up the hierarchy may be due to the very high dominance scores of the first- and second-ranking males, which may have created a perceptible barrier. The positive relationship between grooming an individual and being tolerated in close proximity of this individual more often and longer during feeding suggests that grooming may be beneficial. Grooming and feeding did not necessarily co-occur. Males that groomed dominant males more often also received more aggression from them, but aggression was mainly of low intensity; thus feeding benefits may outweigh the costs of aggression when staying close to dominants. We did not find an interchange of grooming for agonistic support, which may be explained in 2 ways: First, agonistic support does not play a crucial role 
for males because most of the conflicts were already resolved at a dyadic level. Second, support occurred at a very low rate; thus, our data may not be sufficient to detect such interchange. The latter explanation gains support from the fact that primates are long-term traders in terms of grooming and coalitions (Schino et al. 2003, 2007). That dominance played a crucial role in male social relationships was especially visible in patterns of agonistic interactions. Dominance-subordination relationships between males were relatively strong, expressed as a high percentage of decided conflicts, a high degree of unidirectionality in the exchange of dominance behavior and submission respectively, and in a small percentage of counteraggression of all dyadic conflicts as well as conflicts with aggression.

A second major characteristic of male-male social relationships in stumptail macaques is a very low overall interaction rate, expressed not only in terms of friendly behavior such as staying in proximity, body contact, and grooming, but also in agonistic behavior and especially aggression. Males seemed to avoid each other, thus preventing costly conflicts and severe injuries, which are more common among males because of their large canine size (Ruehlmann et al. 1988). This is in line with other studies, showing that females are more involved in group cohesion and affiliation, whereas males are more engaged in self-directed behavior (Bernstein 1980; Lopez-Lujan et al. 1989). A low interaction rate in grooming may also account for why adjacent ranks did not groom more often than nonadjacent ranks did, as would be predicted by Seyfarth's model (Seyfarth 1977). As overall grooming activity was low, males could choose to groom males of any rank above them, without being restricted by the nonavailability of a grooming partner. Thus, competition for high-ranking grooming partners was probably low.

\section{Comparing Social Relationships}

To provide a scale for interpreting the results, we plotted our data on stumptail macaque males together with data from de Waal and Luttrell (1989) on a mixed group of rhesus macaques ( $83 \%$ females), classified as very intolerant, and a group of stumptail macaques ( $86 \%$ females), classified as tolerant (Fig. 4). These are the only data available entailing a wide range of social traits for the same group. Because these comparison groups consist mainly of females, we assume that the values reflect mainly female-female relationships. Male stumptail macaques fall either on the left side of rhesus macaques, thus indicating for some traits even more intolerance than rhesus macaques (approach rate, grooming duration, threat rate, attack rate), or they fall between rhesus macaques and stumptail macaques, still being more intolerant than the latter (proportion of severe conflicts, predictability of aggression direction). Only in the case of counteraggression, the values for stumptail macaque males are higher than for both the rhesus and stumptail macaque groups.

The comparison may be confounded in 2 ways: First, both comparative data sets from de Waal and Luttrell (1989) are from a captive environment and second, data for the current study were collected under provisioned conditions. Influences of both factors are described elsewhere (effects of crowded conditions: Judge and de Waal 1997; effects of provisioning: Altmann and Muruthi 1988; Oi 1990; Southwick et al. 1976), but data on the influence of provisioning on wild macaques are lacking. However, because tolerant relationships occur in female stumptail macaques (de 
Fig. 4 Tolerance level of stumptail macaque males (StM) in relation to intolerant rhesus macaques (Rh; Macaca mulatta, $83 \%$ females) and tolerant stumptail macaque (St; Macaca arctoides, 86\% females). All behavioral variables are plotted from left to right with increasing tolerance; thus, some axes were reversed. Data used for this figure are given in Table II.

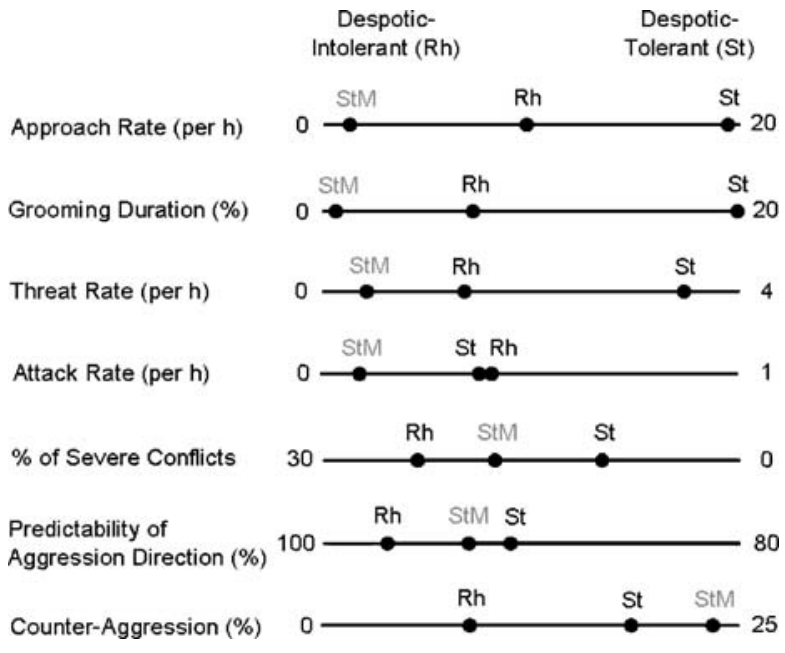

Waal and Luttrell 1989) and also other macaque species (Petit et al. 1997; Silk 1994; Thierry 1985) under captive and thus provisioned conditions, provisioning cannot be a full explanation of intolerant relationships between male stumptail macaques in our focal group.

Our study suggests that male stumptail macaques differ in the quality of social relationships from their female conspecifics. Such sex differences also occur in other macaque species (Berman et al. 2007; Cooper and Bernstein 2002; Preuschoft and Paul 2000; Preuschoft et al. 1998; Reed et al. 1997). For stumptail macaques, resource-holding power differences between males are relatively large, as they show obvious differences in body size. Thus, it is possible to establish strong dominance relationships and intolerant relationships between males in the study group, in contrast to the stalemate situation proposed for Barbary macaques (Macaca sylvanus: Preuschoft and Paul 2000).

Comparative data on other macaque males are available for some behavioral traits. Male stumptail macaques sit nearly 3 times more often in proximity of other males than male bonnet macaques (Macaca radiata, captive, 0.43/h: Silk 1994) but less often than male Assamese macaques (Macaca assamensis, provisioned, $1.66 \pm$ 0.83/h, $\mathrm{N}=11$ males: Cooper, pers. comm.). Male stumptail macaques also groomed less than male Assamese macaques (Macaca assamensis, free-ranging, $0.20 \pm 0.05 / \mathrm{h}$, $N=11$ males: Cooper and Bernstein 2008) and male rhesus macaques (Macaca mulatta, captive, $0.016 \pm 0.001 / \mathrm{h}$ per dyad: Drickamer 1976); male stumptail macaques in this study: $0.004 / \mathrm{h}$ per dyad. For counteraggression, data of other male macaques are plotted with data from this study on male stumptail macaques in Fig. 5a. As there is only 1 other datum point available for grade 3 species, it is difficult to draw a precise conclusion. More data are needed to evaluate intra- and interspecific variation in male behavior, but it appears that male stumptail macaques may fit well into the counteraggression range of grade 2 species.

In general, a despotic social style is thought to be linked to a steep hierarchy (van Schaik 1989). The steepness of female dominance hierarchies (NormDS values) are plotted against social style grade for several macaque species in Fig. 5b. Most of the 

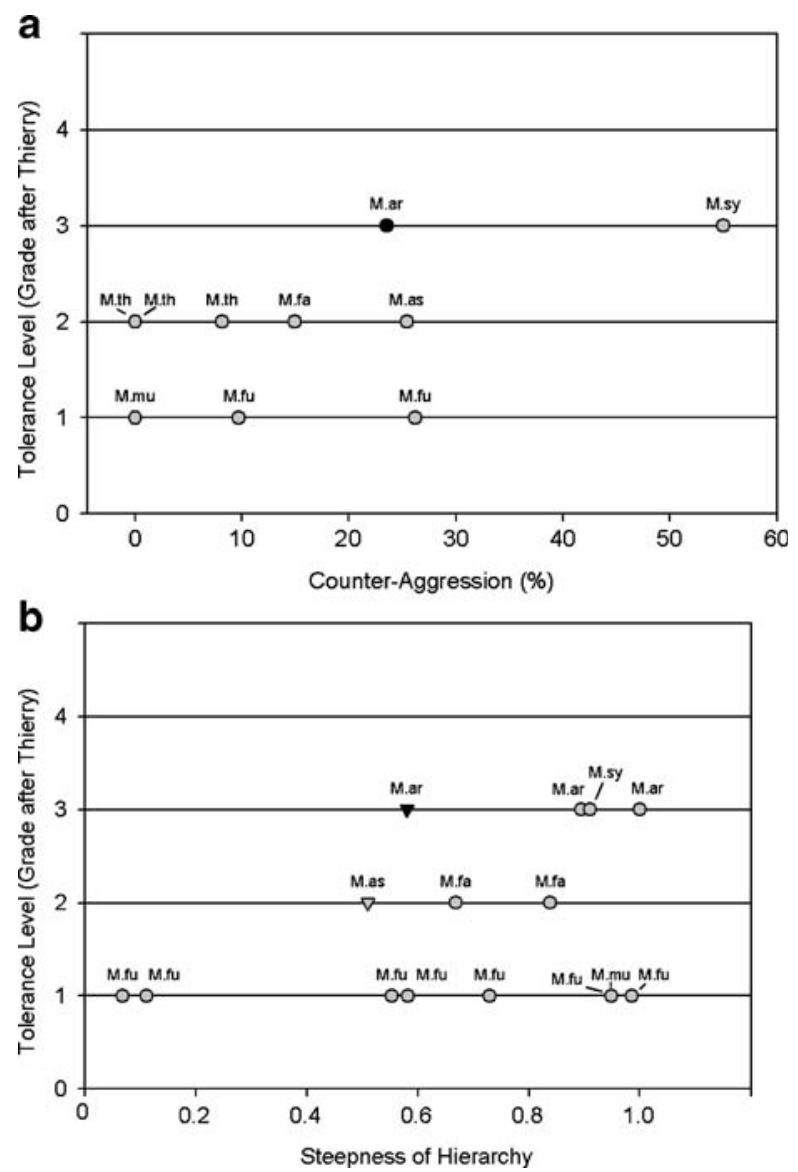

Fig. 5 Tolerance level (grades after Thierry 2007b) in relation to (a) percentage of counteraggression for male-male dyads of different macaque species and (b) steepness of hierarchy (calculated via the Normalized David Scores) of male (triangles) or female (dots) macaques. M.ar = Macaca arctoides; M.as = Macaca assamensis; M.fa = Macaca fascicularis; M.fu = Macaca fuscata; M.mu = Macaca mulatta; M.sy = Macaca sylvanus; M.th = Macaca thibetana . Sources from left to right and bottom to top: (a) $\mathrm{CA}=$ counteraggression at the group level, except values marked with *, which represent mean values: M.mu (Thierry 1985): 0\% CA, 4 ô; M.fu (Thierry 1990): 9.7\% CA, 7 ơ; M.fu (Petit et al. 1997):

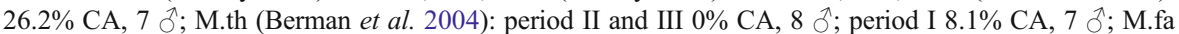
(Thierry 1985): 14.9\% CA, 4 §; M.as (Cooper and Bernstein 2008): 25.4\% CA*, 11 §; M.ar (this study): $23.5 \% \mathrm{CA}^{*}$, at the group level it would be $18.84 \% \mathrm{CA}, 9$ ठ̋; M.sy (Marengo, unpub. data from Thierry and Aureli 2006): 55\% CA* (estimated from graphic), 24 . (b) *Indicates that the steepness was calculated by Schino and Aureli (2008): M.fu (Ventura et al. 2006): 0.07* for Kw group, 20 \%; M.fu (Ventura 1988): 0.11*, 22 क; M.fu (Aureli, unpub.; Arnhem): 0.55*, 9 क; M.fu (Oi 1988): 0.58* for Hanyama-M, 10 \%; M. fu (Ventura et al. 2006): 0.73* for Nina-A group, 8 क; M.fu (Aureli unpub.; Artis): 0.95*, 6 \%; M. mu (Sade 1972): 0.95*, 9 \%; M.fu (Mehlman and Chapais 1988): 0.99*, 6 \%; M.as (Ostner et al. 2008): 0.51, 12 §; M.fa (Butovskaya et al. 1995): 0.67* for L group, 9 ᄋ; M.fa (Butovskaya et al. 1995): $0.84 *$ for H group, 7 o; M.ar (this study): 0.58, 9 §̊; M.ar (Rhine 1972): 0.89*, 4 O; M.sy (Fa 1985): 0.91*, 4 क; M.ar (Estrada et al. 1977): 1.00*, 5 q. 
apparent variation in steepness of the hierarchy can be attributed to variation in hierarchy size (overall $N=15, r=0.93, p<0.001$ ) even on the species level (Macaca fuscata $N=6, r=0.96, p<0.001$ ), which Schino and Aureli (2008) showed in previous analyses. Nevertheless, analyzing species means steepness of the hierarchy correlates negatively with social style grade when the effect of group size is partialled out $(N=6, r=-0.89, p<0.04)$. Thus, across macaques, the female hierarchy is the shallower the higher the social style grade as predicted by socioecological theory. Male stumptail macaques fall well within this pattern derived from female social relationships.

\section{Conclusions}

We aimed to provide comparative data on male stumptail macaques by describing details of male social relationships. Our results indicate 1) that male stumptail macaques are more intolerant than previously predicted based on most behavioral traits investigated and 2) that males and females differ in their social style. Both findings are in line with predictions based on socioecological reasoning in light of sex-differential resource characteristics (Clutton-Brock 1989; Emlen and Oring 1977; Wrangham 1980).

Acknowledgments We thank the National Research Council of Thailand (NRCT) for permission to conduct this study (project ID: 0002.3/ 4823). We thank Abbot Pra Bi Deegachom and the monks of Wat Khuha Santayaram for permission to work on their premises and their generous hospitality as well as Phithak Mektrong for logistical support. We thank Roger Mundry for statistical advice, Han de Vries for help with the David Score, and Joanna Setchell and 3 anonymous reviewers for very helpful comments. We thank Matthew Cooper for providing information on approach data for Assamese macaques. The study was part of the diploma research of C. Richter at the University of Leipzig. The Max Planck Society provided financial support.

Open Access This article is distributed under the terms of the Creative Commons Attribution Noncommercial License which permits any noncommercial use, distribution, and reproduction in any medium, provided the original author(s) and source are credited.

\section{References}

Altmann, J. (1974). Observational study of behavior: sampling methods. Behaviour, 49, 227-267.

Altmann, J., \& Muruthi, P. (1988). Differences in daily life between semiprovisioned and wild-feeding baboons. American Journal of Primatology, 15, 213-221.

Barrett, L., Henzi, S., Weingrill, T., Lycett, J., \& Hill, R. (1999). Market forces predict grooming reciprocity in female baboons. Proceedings of the Royal Society of London Series B, 266, 665-670.

Berman, C. M., Ionica, C. S., \& Li, J. (2004). Dominance style among Macaca thibetana on Mt. Huangshan, China. International Journal of Primatology, 25, 1283-1312.

Berman, C. M., Ionica, C., \& Li, J. (2007). Supportive and tolerant relationships among male Tibetan macaques at Huangshan, China. Behaviour, 144, 631-661.

Bernstein, I. (1980). Activity patterns in a stumptail macaque group (Macaca arctoides). Folia Primatologica, 33, 20-45.

Bertrand, M. (1969). The behavioral repertoire of the stumptail macaque. Basel: S. Karger.

Butovskaya, M. (1993). Kinship and different dominance styles in groups of three species of the genus Macaca (M. arctoides, M. mulatta, M. fascicularis). Folia Primatologica, 60, 210-224. 
Butovskaya, M., Kozintsev, A., \& Welker, C. (1995). Grooming and social rank by birth: the case of Macaca fascicularis. Folia Primatologica, 65, 30-33.

Caldecott, J. (1986). Mating patterns, societies and the ecogeography of macaques. Animal Behaviour, 34, 208-220.

Castles, D. L., Aureli, F., \& de Waal, F. B. M. (1996). Variation in conciliatory tendency and relationship quality across groups of pigtail macaques. Animal Behaviour, 52, 389-403.

Chaffin, C. L., Friedlen, K., \& de Waal, F. B. M. (1995). Dominance style of Japanese macaques compared with rhesus and stumptail macaques. American Journal of Primatology, 35, 103-116.

Clutton-Brock, T. H. (1989). Mammalian mating systems. Proceedings of the Royal Society London B, 236, 339-372.

Cooper, M. A., \& Bernstein, I. S. (2002). Counter aggression and reconciliation in Assamese macaques (Macaca assamensis). American Journal of Primatology, 56, 215-230.

Cooper, M. A., \& Bernstein, I. S. (2008). Evaluating dominance styles in Assamese and rhesus macaques. International Journal of Primatology, 29, 225-243.

de Vries, H. (1993). The rowwise correlation between two proximity matrices and the partial rowwise correlation. Psychometrika, 58, 53-69.

de Vries, H. (1995). An improved test of linearity in dominance hierarchies containing unknown or tied relationships. Animal Behaviour, 1375-1389.

de Vries, H. (1998). Finding a dominance order most consistent with a linear hierarchy: a new procedure and review. Animal Behaviour, 55, 827-843.

de Vries, H., Stevens, J., \& Vervaecke, H. (2006). Measuring and testing the steepness of dominance hierarchies. Animal Behaviour, 71, 585-592.

de Waal, F. B. M., \& Luttrell, L. M. (1989). Toward a comparative socioecology of the genus Macaca: different dominance styles in rhesus and stumptailed macaques. American Journal of Primatology, 19, 83-109.

de Waal, F., \& Ren, R. (1988). Comparison of the reconciliation behavior of stumptail and rhesus macaques. Ethology, 78, 129-142.

Drickamer, L. (1976). Quantitative observations of grooming behavior in free-ranging Macaca mulatta. Primates, 17, 323-335.

Emlen, S. T., \& Oring, L. W. (1977). Ecology, sexual selection, and the evolution of mating systems. Science, 197, 215-223.

Estrada, A., Estrada, R., \& Ervin, F. (1977). Establishment of a free-ranging colony of stumptail macaques (Macaca arctoides): social relations I. Primates, 18, 647-676.

Fa, J. E. (1985). Use of time and resources by provisioned troops of monkeys: Social behaviour, time and energy in the Barbary macaque (Macaca sylvanus L.) at Gibraltar. Basel: Karger.

Fedigan, L., \& Jack, K. (2004). The demographic and reproductive context of male replacements in Cebus capucinus. Behaviour, 141, 755-775.

Freeman, L. C., Freeman, S. C., \& Romney, A. K. (1992). The implications of social structure for dominance hierarchies in red deer, Cervus elaphus L. Animal Behaviour, 44, 239-245.

Gammell, M., de Vries, H., Jennings, D., Carlin, C., \& Hayden, T. (2003). David's score: a more appropriate dominance ranking method than Clutton-Brock et al.'s index. Animal Behaviour, 66, 601605.

Goodall, J. (1965). Chimpanzees of the Gombe stream reserve. In I. DeVore (Ed.), Primate behaviour (pp. 425-473). New York: Holt, Rinehart and Winston.

Goodall, J. (1986). The chimpanzee of Gombe: Patterns of behavior. Cambridge, MA: Harvard University Press.

Gould, L. (1997). Intermale affiliative behavior in ringtailed lemurs (Lemur catta) at the Beza-Mahafaly Reserve, Madagascar. Primates, 38, 15-30.

Haccou, P., \& Meelis, E. (1997). Statistical analyses of behavioural data: An approach based on timestructured models. Oxford: Oxford University Press.

Hemelrijk, C., \& Gygax, L. (2004). Dominance style, differences between the sexes and species. An agent-based model. Interaction Studies, 5, 131-146.

Hemelrijk, C. K., Wantia, J., \& Gygax, L. (2005). The construction of dominance order: comparing performance of five methods using an individual-based model. Behaviour, 142, 1043-1064.

Hill, D. A. (1994). Affiliative behaviour between adult males of the genus Macaca. Behaviour, 130, 293308.

Hill, D. A., \& van Hooff, J. A. R. A. M. (1994). Affiliative relationships between males in groups of nonhuman primates: a summary. Behaviour, 130, 143-149.

Hinde, R. (1976). Interactions, relationships and social structure. Man, 11, 1-17. 
Jack, K., \& Fedigan, L. (2004). Male dispersal patterns in white-faced capuchins, Cebus capucinus-part 1: patterns and causes of natal emigration. Animal Behaviour, 67, 761-769.

Judge, P. G., \& de Waal, F. B. M. (1997). Rhesus monkey behaviour under diverse population densities: coping with long-term crowding. Animal Behaviour, 54, 643-662.

Kappeler, P. M., \& van Schaik, C. P. (2002). Evolution of primate social systems. International Journal of Primatology, 23, 707-740.

Kummer, H. (1968). Social organization of hamadryas baboons. Chicago: University of Chicago Press.

Langergraber, K. E., Mitani, J. C., \& Vigilant, L. (2007). The limited impact of kinship on cooperation in wild chimpanzees. PNAS, . doi:10.1073/pnas.0611449104.

Lopez-Lujan, A. X., Ramirez Ochoa, I., Mayagoitia, L., \& Mondragon-Ceballos, R. (1989). Sex differences in intra-group spacing behavior in stumptailed macaques (Macaca arctoides). Folia Primatologica, 52, 102-108.

MacKenzie, M., McGrew, W. C., \& Chamove, A. (1985). Social preferences in stump-tailed macaques (Macaca arctoides): effects of companionship, kinship, and rearing. Developmental Psychobiology, $18,115-123$.

Malaivijitnond, S., \& Hamada, Y. (2005). A new record of stump-tailed macaques in Thailand and the sympatry with long-tailed macaques. The Natural History Journal of Chulalongkorn University, 5, 93-96.

Martin, P., \& Bateson, P. (1993). Measuring behaviour. Cambridge, UK: Cambridge University Press.

Matsumura, S. (1999). The evolution of "egalitarian" and "despotic" social systems among macaques. Primates, 40, 23-31.

Mehlman, P., \& Chapais, B. (1988). Differential effects of kinship, dominance, and the mating season on female allogrooming in a captive group of Macaca fuscata. Primates, 29, 195-217.

Noë, R., \& Sluijter, A. A. (1995). Which adult male savanna baboons form coalitions? International Journal of Primatology, 16, 77-105.

Oi, T. (1988). Sociological study on the troop fission of wild Japanese monkeys (Macaca fuscata yakui) on Yakushima island. Primates, 29, 1-19.

Oi, T. (1990). Patterns of dominance and affiliation in wild pig-tailed macaques (Macaca nemestrina nemestrina) in West Sumatra. International Journal of Primatology, 11, 339-356.

Ostner, J., \& Kappeler, P. M. (2004). Male life history and the unusual adult sex ratio in redfronted lemurs (Eulemur fulvus rufus) groups. Animal Behaviour, 67, 249-259.

Ostner, J., Heistermann, M., \& Schülke, O. (2008). Dominance, aggression and physiological stress in wild male Assamese macaques (Macaca assamensis). Hormones and Behavior, 54, 613-619.

Packer, C. (1979). Male dominance and reproductive activity in Papio anubis. Animal Behaviour, 27, 37-45.

Packer, C., Gilbert, D. A., Pusey, A. E., \& O’Brien, S. J. (1991). A molecular genetic analysis of kinship and cooperation in African lions. Nature, 351, 562-565.

Petit, O., Abegg, C., \& Thierry, B. (1997). A comparative study of aggression and conciliation in three cercopithecine monkexs (Macaca fuscata, Macaca nigra, Papio papio). Behaviour, 134, 415-432.

Pope, T. (1990). The reproductive consequences of male cooperation in the red howler monkey: paternity exclusion in multi-male and single-male troops using genetic markers. Behavioral Ecology and Sociobiology, 27, 439-446.

Preuschoft, S., \& Paul, A. (2000). Dominance, egalitarianism, and stalemate: An experimental approach to male-male competition in Barbary macaques. In P. Kappeler (Ed.), Primate males: Causes and consequences of variation in group composition (pp. 205-216). Cambridge, UK: Cambridge University Press.

Preuschoft, S., Paul, A., \& Kuester, J. (1998). Dominance styles of female and male Barbary macaques (Macaca sylvanus). Behavior, 135, 731-755.

Reed, C., O’Brien, T. G., \& Kinnaird, M. F. (1997). Male social behavior and dominance hierarchy in the Sulawesi crested macaque (Macaca nigra). International Journal of Primatology, 18, 247-260.

Rhine, R. (1972). Changes in the social structure of two groups of stumptial macaques (Macaca arctoides). Primates, 13, 181-194.

Ruehlmann, T. E., Bernstein, I. S., Gordon, T. P., \& Balcaen, P. (1988). Wounding patterns in three species of captive macaques. American Journal of Primatology, 14, 125-134.

Sade, D. S. (1972). Sociometrics of Macaca mulatta. I. Linkages and cliques in grooming matrices. Folia Primatologica, 18, 196-223.

Schino, G., \& Aureli, F. (2008). Trade-offs in primate grooming reciprocation: testing behavioural flexibility and correlated evolution. Biological Journal of the Linnean Society, 95, 439-446.

Schino, G., Ventura, R., \& Troisi, A. (2003). Grooming among female Japanese macaques: distinguishing between reciprocation and interchange. Behavioral Ecology, 14, 887-891. 
Schino, G., di Sorrentino, E. P., \& Tiddi, B. (2007). Grooming and coalitions in Japanese macaques (Macaca fuscata): partner choice and the time frame of reciprocation. Journal of Comparative Psychology, 121, 181-188.

Seyfarth, R. (1977). A model of social grooming among female monkeys. Journal of Theoretical Biology, $65,671-698$.

Silk, J. (1992). Patterns of intervention in agonistic contests among male bonnet macaques. In A. Harcourt \& F. De Waal (Eds.), Coalitions and alliances in humans and other animals (pp. 215-232). Oxford: Oxford University Press.

Silk, J. B. (1994). Social relationships of male bonnet macaques: male bonding in a matrilineal society. Behaviour, 130, 271-291.

Southwick, C. H., Siddiqi, M. F., Farrooqui, M. Y., \& Chandra Pal, B. (1976). Effects of artificial feeding on aggressive behaviour of rhesus monkeys in India. Animal Behaviour, 24, 11-15.

Starin, E. D. (1994). Philopatry and affiliation among red colobus. Behaviour, 130, 253-270.

Sterck, E. H. M., Watts, D. P., \& van Schaik, C. P. (1997). The evolution of female social relationships in nonhuman primates. Behavioral Ecology and Sociobiology, 41, 291-309.

Strier, K. B. (1994). Brotherhoods among atelins: kinship, affiliation, and competition. Behaviour, 130, $151-167$.

Struhsaker, T. T. (1975). The red colobus monkey. Chicago: University of Chicago Press.

Struhsaker, T. T., \& Leland, L. (1987). Colobines: Infanticide by adult males. In B. B. Smuts, D. L. Cheney, R. M. Seyfarth, R. W. Wrangham \& T. T. Struhsaker (Eds.), Primate societies (pp. 83-97). Chicago: University of Chicago Press.

Thierry, B. (1985). Patterns of agonistic interactions in three species of macaque (Macaca mulatta, M fascicularis, $M$ tonkeana). Aggressive Behavior, 11, 223-233.

Thierry, B. (1990). The state of equilibrium among agonistic behavior patterns in a group of Japanese macaques (Macaca fuscata). Comptes Rendus de l'Académie des Sciences. Série III, Sciences de la Vie, 310, 35-40.

Thierry, B. (2000). Covariation of conflict management patterns across macaque species. In F. Aureli \& F. De Waal (Eds.), Natural conflict resolution (pp. 106-128). Berkley: University of California Press.

Thierry, B. (2004). Social epigenesis. In B. Thierry, M. Singh \& W. Kaumanns (Eds.), Macaque societies: A model for the study of social organization (pp. 267-289). Cambridge, UK: Cambridge University Press.

Thierry, B. (2007a). The macaques: A double-layered social organization. In C. Campbell, A. Fuentes \& K. MacKinnon (Eds.), Primate in perspective (pp. 224-239). New York: Oxford University Press.

Thierry, B. (2007b). Unity in diversity: lessons from macaque societies. Evolutionary Anthropology, 16, $224-238$.

Thierry, B., \& Aureli, F. (2006). Barbary but not barbarian: Social relations in a tolerant macaque. In J. K. Hodges \& J. Cortes (Eds.), The Barbary macaque: Biology, management and conservation (pp. 2945). Nottingham, UK: Nottingham University Press.

Thierry, B., Iwaniuk, A. N., \& Pellis, S. M. (2000). The influence of phylogeny on the social behaviour of macaques (Primates: Cercopithecidae, genus Macaca). Ethology, 106, 713-728.

van Hooff, J. A. R. A. M. (1967). The facial displays of the catarrhine monkeys and apes. In D. Moris (Ed.), Primate ethology (pp. 7-68). London: Weidenfeld and Nicholson.

van Hooff, J. A. R. A. M., \& van Schaik, C. P. (1992). Cooperation in competition: The ecology of primate bonds. In A. H. Harcourt \& F. B. M. de Waal (Eds.), Coalitions and alliances in humans and other animals (pp. 357-389). Oxford: Oxford University Press.

van Hooff, J. A. R. A. M., \& van Schaik, C. P. (1994). Male bonds: affiliative relationships among nonhuman primate males. Behaviour, 130, 309-337.

van Hooff, J. A. R. A. M., \& van Wensing, J. A. B. (1987). Dominance and its behavioural measures in a captive wolf pack. In H. Frank (Ed.), Man and wolf (pp. 219-252). Dordrecht: Junk.

van Schaik, C. P. (1989). The ecology of social relationships amongst female primates. In V. Standen \& R. A. Foley (Eds.), Comparative socioecology. The behavioural ecology of humans and other mammals (pp. 195-218). Oxford: Blackwell.

van Schaik, C. P. (1996). Social evolution in primates: the role of ecological factors and male behaviour. Proceedings of the British Academy, 88, 9-31.

Ventura, R. (1988). La distribuzione dell'allogrooming tra le femmine di macaco del Giappone (Macaca fuscata). Italy: Università La Sapienza.

Ventura, R., Majola, B., Koyama, N., Hardie, S., \& Schino, G. (2006). Reciprocation and interchange in wild japanese macaques: grooming, cofeeding, and agonistic support. American Journal of Primatology, 68, 1138-1149. 
Vervaecke, H., de Vries, H., \& van Elsacker, L. (2000). The pivotal role of rank in grooming and support behavior in a captive group of bonobos (Pan paniscus). Behaviour, 137, 1463-1485.

Vervaecke, H., Stevens, J. M. G., Vandemoortele, H., Sigurjónsdóttir, H., \& de Vries, H. (2007). Aggression and dominance in matched groups of subadult Icelandic horses (Equus caballus). Journal of Ethology, 25, 239-248.

Widdig, A., Streich, W., \& Tembrock, G. (2000). Coalition formation among male Barbary macaques (Macaca sylvanus). American Journal of Primatology, 50, 37-51.

Wrangham, R. W. (1980). An ecological model of female-bonded primate groups. Behaviour, 75, 262300 . 